\title{
UMA CARTA DE STÉPHANE MALLARMÉ A ODILON REDON Caroline Micaelia ${ }^{l}$
}

RESUMO: No âmbito da extensa correspondência de Stéphane Mallarmé, uma carta endereçada a Odilon Redon, talvez a primeira, evidencia algumas correlações entre as poéticas dos dois artistas, colocados em contato através das palavras e dos gestos de Joris-Karl Huysmans. Trata-se da resposta a um envio do pintor - notadamente, a série litográfica Hommage à Goya -, na qual o poeta, através de breves comentários, firma as ligações entre as duas obras e os laços de uma amizade que se estenderá ainda por muitos anos e caminhos. Este trabalho consiste numa tradução da referida carta, seguida pela reprodução das chapas litográficas de Redon que suscitaram os comentários de Mallarmé.

PALAVRAS-CHAVE: Odilon Redon, Stéphane Mallarmé, Hommage à Goya, correspondência, tradução.

\footnotetext{
${ }^{1}$ Caroline Micaelia é tradutora e bacharel em Letras (Português-Francês) pela Universidade de São Paulo e pela Université Paris-Sorbonne (Paris IV).
} 


\section{UNE LETTRE DE STÉPHANE MALLARMÉ À ODILON REDON}

RÉSUMÉ : Dans le cadre de l'extensive correspondance de Stéphane Mallarmé, une lettre adressée à Odilon Redon, peut-être la première, souligne quelques corrélations entre les poétiques des deux artistes mis en contact à travers les mots et les gestes de Joris-Karl Huysmans. Il s'agit de la réponse à un envoi du peintre - à savoir, la série lithographique Hommage à Goya -, où le poète, à partir des brefs commentaires, firme à la fois les liens entre les deux oeuvres et les liaisons d'une amitié qui montera sur les pas des plusieurs années et chemins à venir. $\mathrm{Ce}$ travail consiste dans une traduction de la lettre mentionnée ci-dessus, suivie de la reproduction des planches lithographiques de Redon qui ont suscité les commentaires de Mallarmé.

MOTS-CLÉS : Odilon Redon, Stéphane Mallarmé, Hommage à Goya, correspondance, traduction.

\section{A LETTER FROM STÉPHANE MALLARMÉ TO ODILON REDON}

ABSTRACT: In the scope Stéphane Mallarmé's extensive correspondence, a letter addressed to Odilon Redon, perhaps the first one, highlights some correlations between the poetics of the two artists, put in contact through the words and gestures of Joris-Karl Huysmans. It is, indeed, the response to a work - namely, the lithographic series Hommage à Goya - sent by the painter, where the poet, within brief comments, firms the bounds between the two works as well as the ties of a friendship that will go on for many years and ways to come. This paper consists in a translation for the referred letter, followed by the reproduction of Redon's lithographic plates evoked on Mallarmé's comments.

KEYWORDS: Odilon Redon, Stéphane Mallarmé, Hommage à Goya, correspondence, translation.

\section{APRESENTAÇÃo}

Seria preciso algo muito curioso, para justificar nossa escolha², no lugar de um ilustrador atual; e ao mesmo tempo acessível a todos, como o que pedem a este último. ${ }^{3}$

- Stéphane Mallarmé

\footnotetext{
${ }^{2}$ A escolha de Huysmans por Redon e Mallarmé para À rebours.

3 "Il faudrait quelque chose de fort curieux, pour justifier notre choix, au lieu de celui d'un illustrateur courant; et en même temps accessible à tous, comme ce qu'on demande à ce dernier."
} 
O documento que em breve estará diante do leitor oferece um vislumbre epistolar da já conhecida - e um tanto comentada ${ }^{4}$ - amizade entre Stéphane Mallarmé e Odilon Redon: trata-se, em outras palavras, da tradução de uma carta célebre $^{5}$ - inédita em língua portuguesa -, escrita pelo poeta ao pintor em resposta ao envio do então recém-lançado álbum de litografias Hommage à Goya (1885). O interesse instigado em Mallarmé pelo contato com esse "nouvel album d'Odilon Redon", como o escritor e crítico de arte J. -K. Huysmans o chama, leva aquele a selar, por via privada, através de uma leitura autobiográfica do trabalho de Redon, não apenas a amizade entre os dois artistas, mas também algumas imbricações fundamentais das duas obras, das duas poéticas, dos dois universos. Antes disso, o selo público dessa relação teria vindo com a aparição da novela À rebours (1884), do mesmo Huysmans que promoveria, ainda em 1885, o significativo encontro presencial daquilo que até então teria se dado unicamente por meio de correspondência; registro que, entretanto, nos concede, de certa forma, a dimensão do acontecimento.

Por se tratar de uma carta - algo, portanto, que visa primordialmente a comunicação -, uma tradução que a tivesse em conta simplesmente como fonte, ou como pretexto, poderia, sem dúvidas, ser realizada no sentido de facilitar sua leitura, principalmente tendo em vista que o documento aqui apresentado consiste num texto construído a partir de uma elaboração - formal, mas não só - altamente truncada. Considerando, porém, a poética de Mallarmé, a preocupação do poeta com o trabalho linguístico, sua escrita meticulosamente pensada, mesmo em correspondência ${ }^{6}$, o que se coloca não é apenas quão importantes são as informações que a carta apresenta para fins de pesquisa, mas também o quão enraizado em todas as experiências da linguagem está o estilo mallarmeano. Em elo metonímico com a confluência inesgotável de encontros artísticos que caracteriza a correspondência de Mallarmé, a missiva em questão, transposta ao português, nos reenvia à época do dito simbolismo por entre meandros que reúnem, numa só trilha, os desafios da escrita, do pictural e da tradução.

\footnotetext{
${ }^{4}$ Um bom exemplo é a conferência que Bertrand Marchal deu na ocasião da exposição Odilon Redon, Prince du Rêve, no Grand Palais (Paris), em 2011.

${ }^{5}$ Muito provavelmente uma das primeiras, mesmo isto sendo algo que podemos apenas supor. Para todos os efeitos, é dessa forma que consta nas edições de consulta. Aproveito esta nota pra lembrar (ou contar) ao leitor que a carta em questão é constantemente referida em praticamente toda a produção crítica que se dedicou a pensar as relações entre Redon e Mallarmé.

${ }^{6}$ Basta perceber a diferença entre as cartas enviadas pelo poeta aos amigos e as cartas enviadas por ele a organismos governamentais, como o Ministro da Instrução Pública, por exemplo. Sobre isso - e sobre outros assuntos igualmente interessantes -, ver a tese de doutorado de Sandra Mara Stroparo (2012), Cartas de Mallarmé: leitura, crítica e tradução.
} 


\title{
A TRADUÇÃO ${ }^{7}$
}

\author{
A Odilon Redon
}

Paris, 89 rue de Rome

[Segunda-feira, 2 de fevereiro de 1885]

Monsieur,

Como o senhor me mima! e vai ao encontro de um de meus desejos, que é o de observar longamente uma obra sua. Faz já dois dias que folheio essa sequência extraordinária das seis litografias ${ }^{8}$, sem esgotar minha impressão de nenhuma, tão longe vai a sinceridade na visão, não menos que a potência em evocá-la nos outros. Uma simpatia bem misteriosa fez o senhor retratar nesse delicioso eremita louco ${ }^{9}$ o pobre homenzinho que do fundo de minha alma eu gostaria de ser; e suspendo esse desenho à parte em algum mural de minha memória, para julgar os outros de uma forma mais desinteressada. A cabeça de Sonho, esta "fleur de marécage" 10 , ilumina com uma claridade que ela sabe somente e que não será dita, todo o trágico farol da existência ordinária; e que síntese cruelmente abreviada, aí sem estiolamento, mas quase satisfeita, da face interior de muito, na chapa $\mathrm{IV}^{11}$. O estudo de mulher, que o senhor chama tão certeiramente de deusa do Inteligível ${ }^{12}$, nos escapa a contragosto do pesadelo; mas toda minha admiração vai direto para o grande Mago inconsolável e obstinado investigador de um mistério que ele sabe não existir, e que perseguirá, para sempre por isso, do luto de seu lúcido desespero, porque teria sido $^{13}$ a Verdade! Não conheço nenhum desenho que comunique tanto medo intelectual e simpatia assustadora, apenas esse grandioso rosto ${ }^{14}$. Meu outro preferido é, na mesma ordem de devaneios salomônicos, esse "étrange jongleur" ${ }^{\prime 15}$ de mente devastada pela maravilha de sentido profundo que ele realiza, e tão sofrido no triunfo de seu sabido resultado.

\footnotetext{
${ }^{7}$ Esta tradução foi construída a partir da consulta de duas versões diferentes da carta de Mallarmé: a do segundo volume da Correspondance (recolhida, editada e anotada por Henri Mondor e Lloyd James Austin), de 1965; e a da Correspondance/Lettres sur la poésie (organizada e anotada por Yves Bonnefoy e Bertrand Marchal), de 1995. A maioria das notas presentes na tradução foi retirada deste último volume, motivo pelo qual serão apresentadas como "nota dos editores" (N. dos E.); as notas de tradução, por outro lado, serão "nota da tradutora" (N. da T.). Agradeço a finíssima e mui dedicada revisão de Henrique Amaral, amigo querido e cúmplice indispensável nas aventuras da tradução.

${ }^{8}$ N. dos E.: Hommage à Goya.

${ }^{9} \mathrm{~N}$. dos E.: Chapa III: "Un FOU, dans un morne paysage." (grifo do artista).

10 N. dos E.: Chapa II: "La FLEUR du MARÉCAGE une tête humaine et triste." (grifo do artista).

${ }^{11} \mathrm{~N}$. dos E.: "Il y eût aussi des ÊTRES EMBRYONNAIRES" (grifo do artista).

12 N. dos E.: Chapa VI: "Au réveil j'aperçus la DÉESSE de l'INTELLIGIBLE, au profil sévère et dur." (grifo do artista).

${ }^{13}$ N. da T.: Grifo de Mallarmé.

${ }^{14}$ N. dos E.: Chapa I: "Dans mon rêve, je vis au ciel un VISAGE DE MYSTÈRE." (grifo do artista).

${ }^{15}$ N. dos E.: Chapa V: "Un étrange JONGLEUR." (grifo do artista).
} 
Adoro também as legendas ${ }^{16}$ de uma palavra ou duas, mas de uma justeza que mostra a que ponto o senhor penetra antes no arcano de um assunto.

Eu teria visto essa obra em qualquer lugar, caro Monsieur Redon, que dela tiraria um dos mais raros prazeres de arte, que fossem; mas enviada pelo senhor, vou deixar que adivinhe o quanto ela me é preciosa. Há nisso uma coincidência tão magnífica, que não posso, agradecendo o senhor com efusão, não ver, em todo esse contentamento que me foi causado, muito a amizade de nosso caro Huysmans.

Seu devotado,

STÉPHANE MALLARMÉ.

\section{EM FRANCÊS}

\section{À Odilon Redon}

Paris 89 rue de Rome

[Lundi 2 février 1885 ]

Monsieur,

Comme vous me gâtez ! et venez au devant d'un de mes souhaits, qui était de regarder longuement une oeuvre de vous. Voilà deux jours que je feuillette cette suite extraordinaire des six litographies, sans épuiser l'impression d'aucune, tant va loin votre sincerité dans la vision, non moins que votre puissance à l'évoquer chez autrui. Une sympathie bien mystérieuse vous a fait portraiturer dans ce délicieux hermite fou le pauvre petit homme que du fond de mon âme j'aimerais être ; et je suspends ce dessin à part à quelque mur de ma mémoire, pour juger les autres d'une façon plus désintéressée. La tête de Rêve, cette « fleur de marécage », illumine d'une clarté qu'elle connaît seule et qui ne sera pas dite, tout le tragique falot de l'existence ordinaire ; et quelle synthèse cruellement abrégée, sans étiolement là, mais presque satisfaite, de la face intérieure de beaucoup, dans la planche IV. L'étude de femme, que vous appelez si justement la déesse de l'Intelligible, nous sort à regret du cauchemar ; mais mon admiration tout entière va droit au grand Mage inconsolable et obstiné chercheur d'un mystère qu'il sait ne pas exister, et qu'il poursuivra, à jamais pour cela, du deuil de son lucide désespoir, car c'eût été la Vérité ! Je ne connais pas un dessin qui communique tant de peur intellectuelle et de sympathie affreuse, que ce grandiose visage. Mon autre préféré est, dans le même ordre de songes salomoniques, cet « étrange jongleur » à l'esprit dévasté par la merveille au sens profond qu'il accomplit, et si souffrant dans le triomphe de son savant résultat.

J'adore aussi votre légende d'un mot ou deux, mais d'une justesse qui montre à quel point vous pénétrez avant dans l'arcane de votre sujet.

${ }^{16}$ N. da T.: Como fica claro, optei por deixar as "legendas" de Redon no original. 
J'aurais vu cette oeuvre n'importe où, cher Monsieur Redon, que j'en eusse tiré un des plus rares plaisirs d'art, qui soient ; mais envoyée par vous, je vous laisse à deviner combien elle m'est précieuse. Il y a là une coïncidence si exquise, que je ne puis, tout en vous remerciant avec effusion, ne pas voir, dans tout ce contentement qui m'est causé, beaucoup l'amitié de notre cher Huysmans.

Votre dévoué,

STÉPHANE MALLARMÉ.

\section{O ALBUM}

Hommage à Goya apresenta uma série de seis litografias feitas com tinta da china aplicada sobre velino e introduzidas por uma capa. O álbum conta, em cada gravura, com títulos longos, que comportam alguma literariedade, como bem observa Mallarmé. Na ordem, temos ${ }^{17}$ :

${ }^{17}$ As imagens a serem reproduzidas a seguir são (c) Bibliothèque Nationale de France (BNF). 


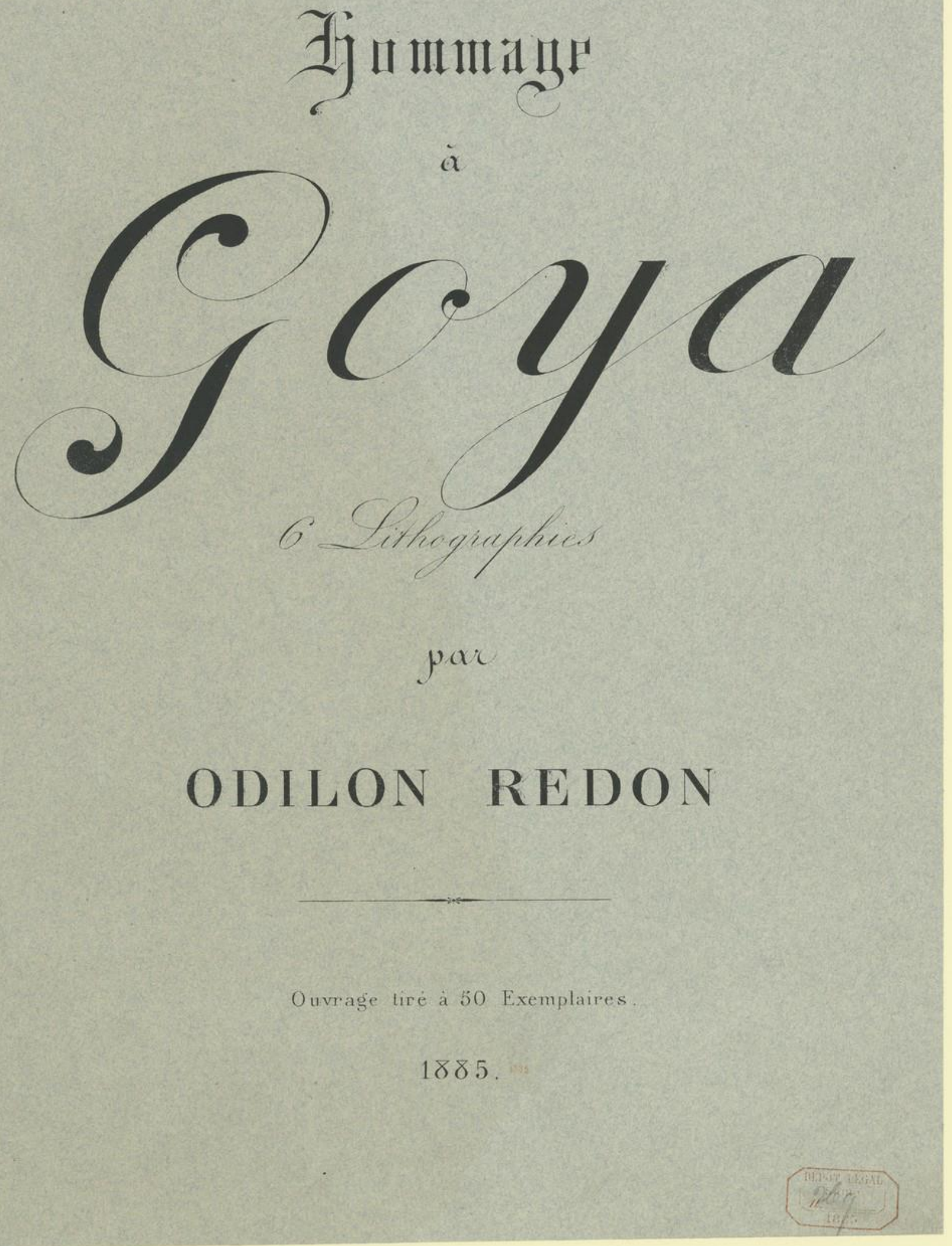


Planche I.

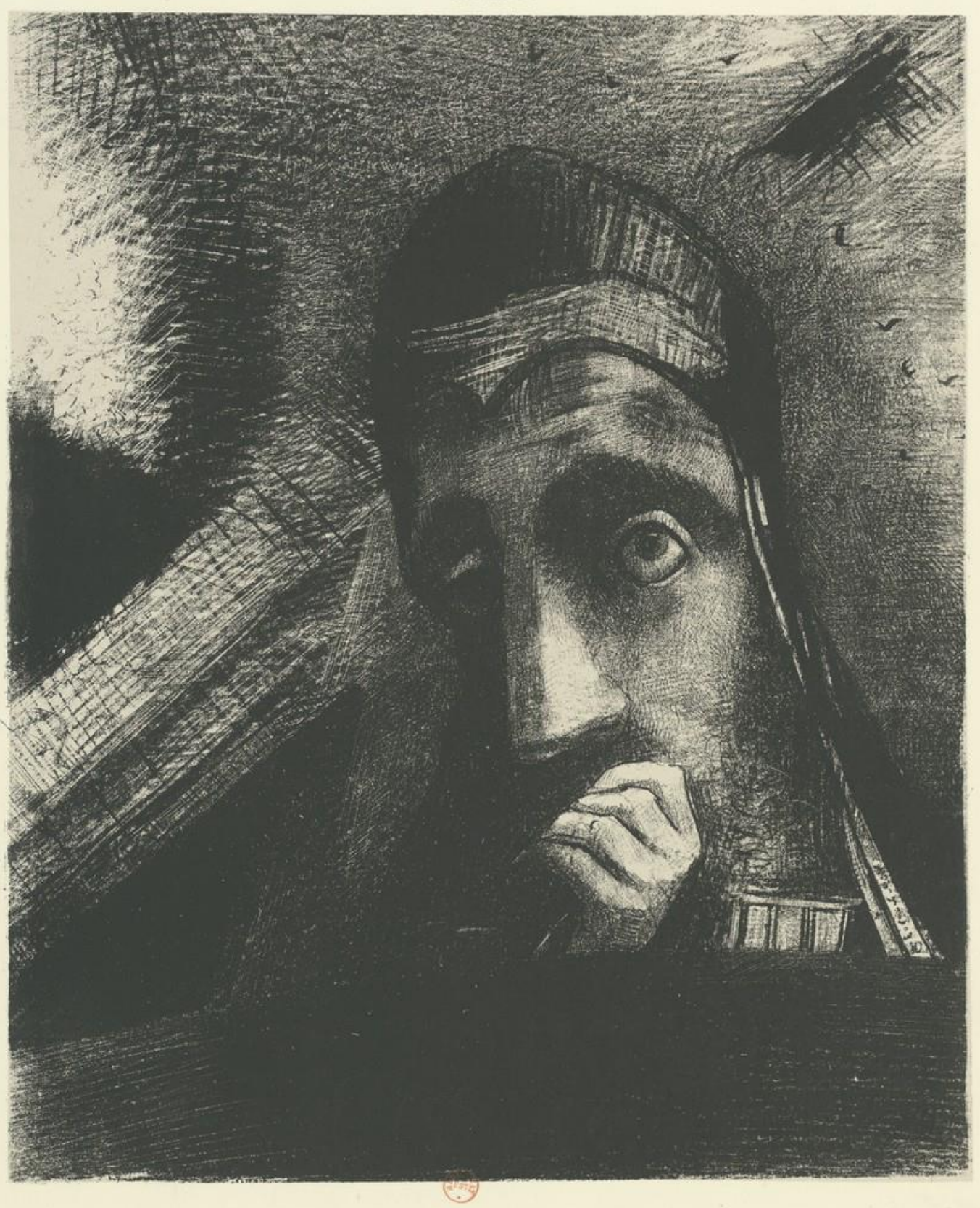

Dans mon rêve, je vis au Ciel un VISAGE DE MYSTÊRE

Source gallica.bnf.fr / Bibliothèque nationale de France 


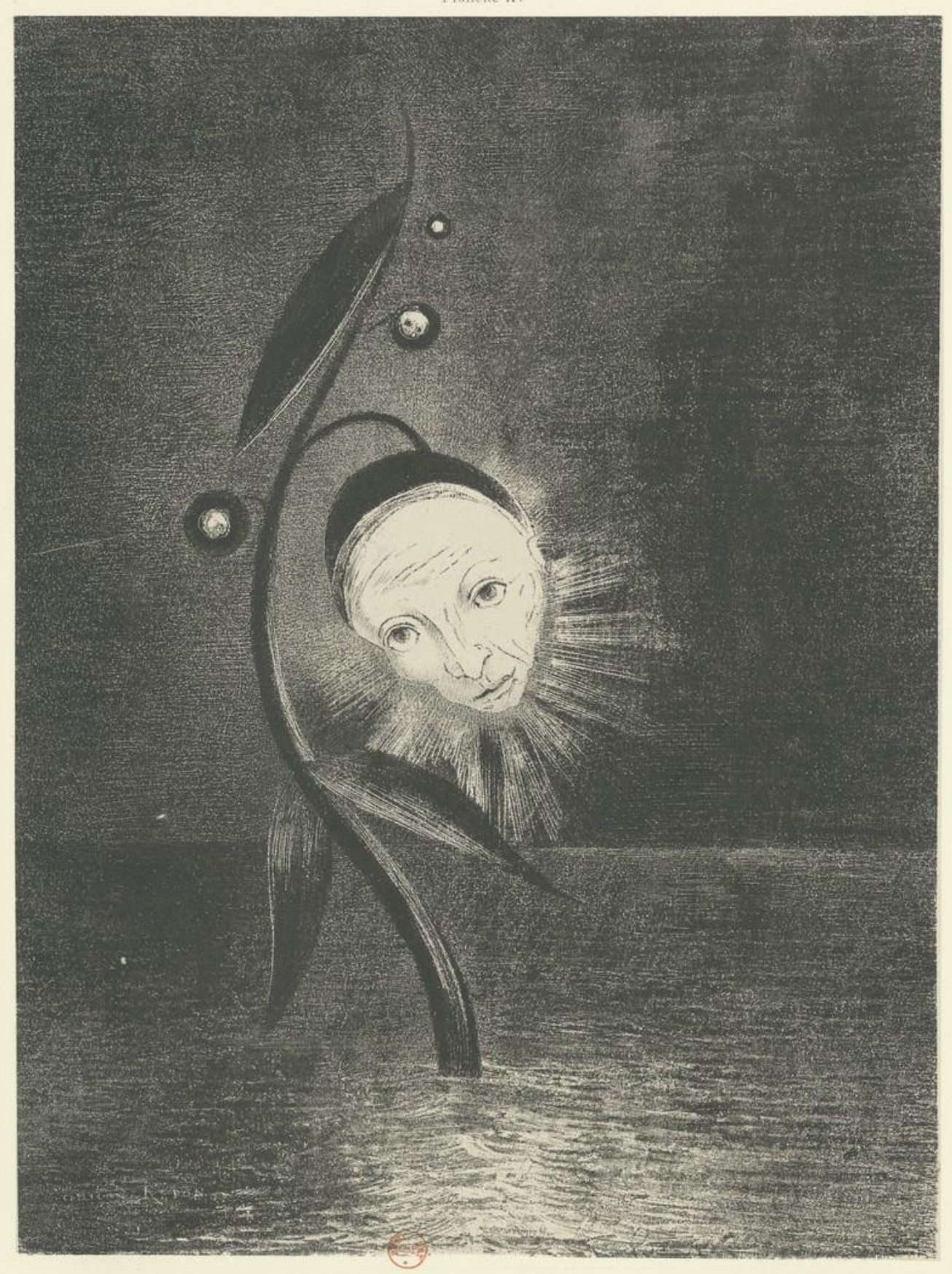

La FLEUR du MARÉCAGE une tête humaine et triste 


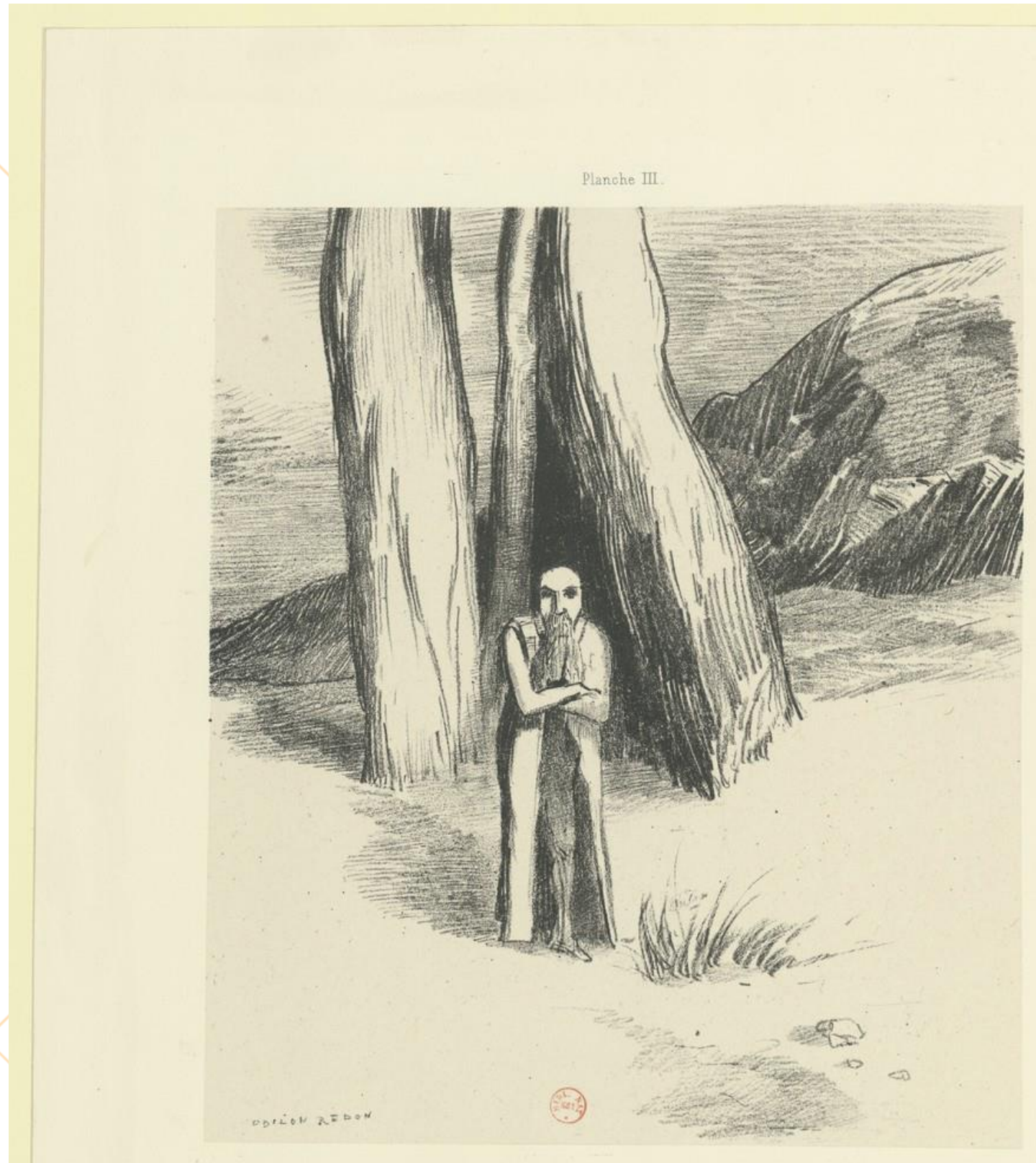

Un FOU, dans, un morne paysage. 


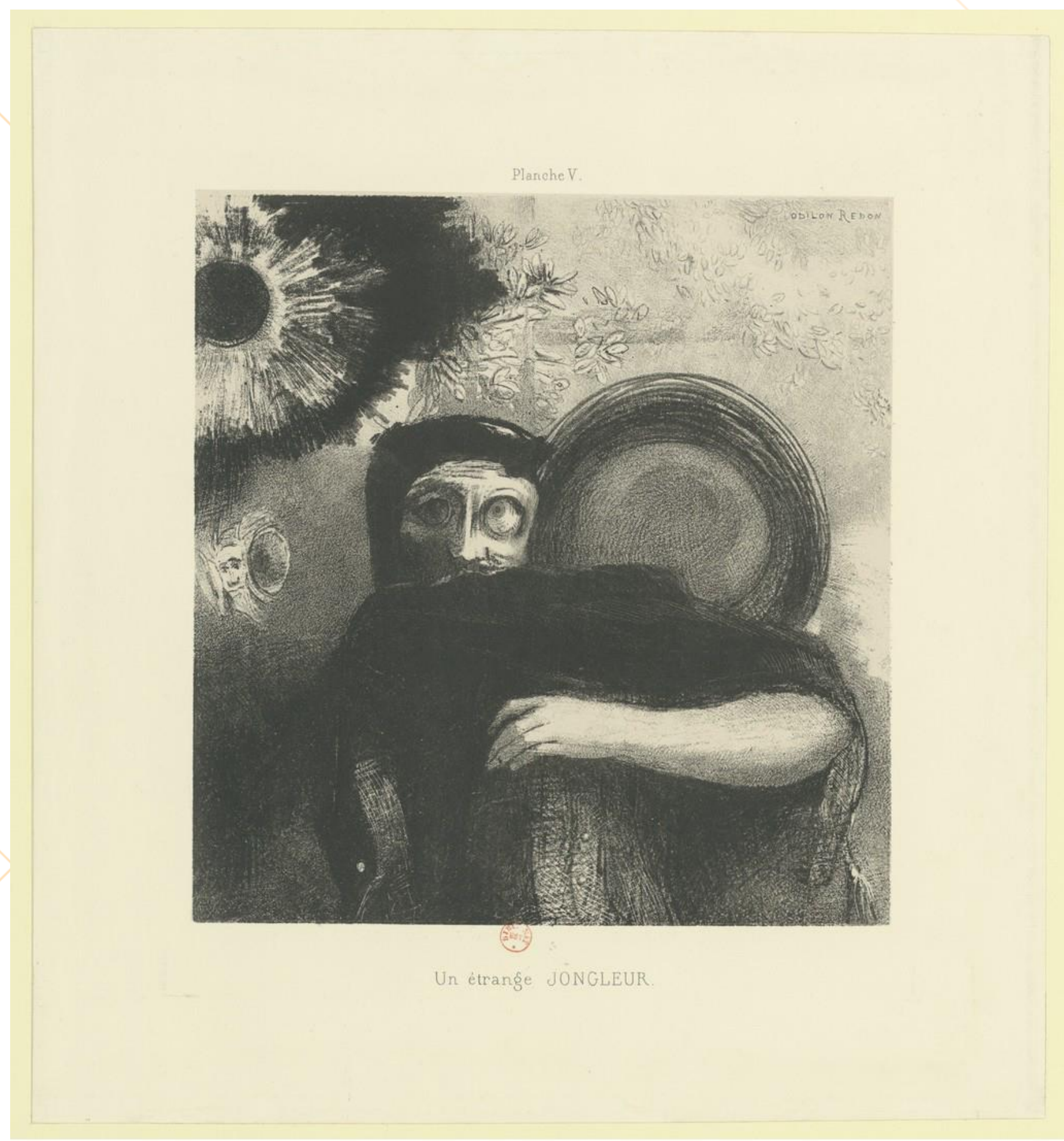

Source gallica.bnf.fr / Bibliothèque nationale de France 


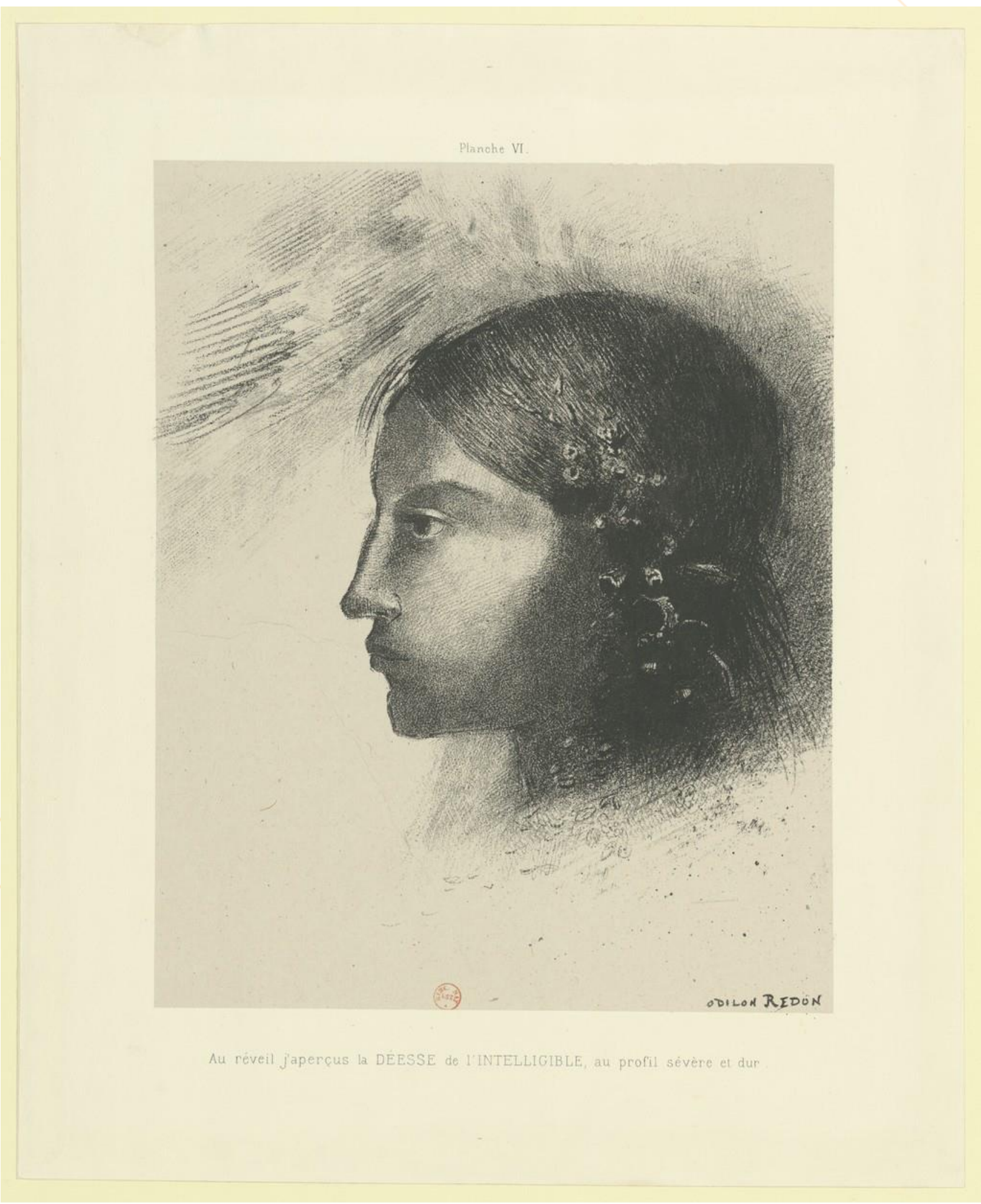




\section{REFERENCIAS BIBLIOGRAFICAS}

MALLARMÉ, Stéphane. Correspondance. Lettres sur la poésie. Édition établie et annotée par Bertrand Marchal. Paris : Folio/Gallimard, 1995.

. Correspondance II: 1871-1885. Édition recueillie, classé et annotée par Henri Mondor et Lloyd James Austin. Paris: Gallimard, 1965.

MARCHAL, Bertrand. Mallarmé et Redon : une amitié en poésie. 2011. Consulté le 21 août 2016. URL : https://www.youtube.com/watch?v=JW3poRITa48.

REDON, Odilon. Hommage à Goya. Paris : 1885. 6 grav., litograph., n\&b, 41,6 x 29,2 et 46,4 x $33 \mathrm{~cm}$ (la feuille). Bibliothèque nationale de France, département Estampes et photographie, RESERVE DC- 354 (4) -BOITE FOL. Consulté le 21 août 2016. URL : http://gallica.bnf.fr/ark:/12148/btv1b6951007f.r=\&rk=21459;2.

STROPARO, Sandra M. Cartas de Mallarmé: leitura, crítica e tradução. 2012. 288 f. Tese de Doutorado - Centro de Comunicação e Expressão, Universidade Federal de Santa Catarina. Florianópolis. 